\title{
 \\ A 2 EL ESPEJO DEL ALMA AL "DIVINO ORÁCULO DE LA ESCRITURA": LA FISIOGNOMÍA Y LA PATOGNOMONÍA SEGÚN BENITO FEIJÓO ${ }^{1}$
}

From the mirror of the soul to the "Divine Oracle of Writing":

On physiognomy and pathognomy on Benito Feijoó

Rodrigo Zapata Cano ${ }^{2}$

\section{Resumen}

El Benedictino español Benito Feijóo (1676-1764), escribió el Teatro Crítico Universal (1726-1740) y las Cartas Eruditas y Curiosas (1742-1760). Se trata de una recopilación enciclopédica que, desde la óptica de la teología natural, abarca un buen número de ensayos sobre la ciencia y los saberes eruditos y populares de la época. Este artículo describe el examen que el padre realiza sobre lo que comprendía como dos tipos de fisiognomía y las consecuencias teológicas, sociales y culturales que extrae de dicho saber.

${ }^{1}$ Este artículo hace parte de la tesis Saberes y creencias sobre el cuerpo en el Teatro Crítico y las Cartas Eruditas y Curiosas del padre Benito Feijóo, presentada en la Facultad de Ciencias Humanas y Económicas, Maestría en Historia (énfasis en Producción, apropiación y circulación de saberes) Universidad Nacional de Colombia, Sede de Medellín, 2007.

${ }^{2}$ Historiador. Docente universitario. Actualmente imparte la cátedra CTS en el INSTITUTO TECNOLÓGICO METROPOLITANO de Medellín, Colombia. Contacto: rodrigozapatak@yahoo.com

Fecha de recepción: 18 de agosto de 2010 Fecha de aceptación: 5 de octubre de 2010
Palabras clave: Benito Feijóo, Ilustración española, cuerpo, saberes, creencias, teología natural, fisiognomía.

\section{Abstract}

Benito Feijoó (1676-1764) was a Spanish Benedict monk. He wrote Teatro Crítico Universal (1726-1740) and Cartas Eruditas y Curiosas (1742-1760). These works are an encyclopedic compilation that, from the point of view of the natural theology, cover a wide range of essays about science and scholarly and popular knowledge at that time. This article describes the revision that Feijoó made of what he understood as two types of physiognomy and the theological, social and cultural consequences that he draws from such knowledge.

Key words: Benito Feijoó, Spanish Illustration, body, knowledge, believes, natural theology, physiognomy 


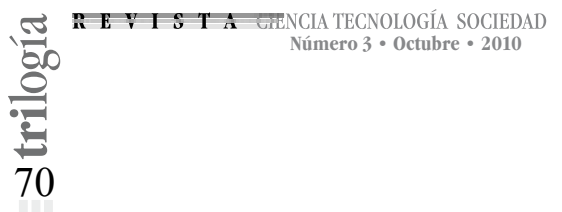

...Y vio al Hombre, a quien buscaba, en un campo pedregoso, que arrancaba con las uñas y los dientes las escasas hierbas. Su cabello era hirsuto, sus ojos hundidos, el rostro pálido, los labios blanqueados por la suciedad (de una barba), la garganta áspera por la ronquera; su piel dura, a través de la cual podían apreciarse sus entrañas; sus huesos descarnados sobresalían bajo la curva de la región lumbar; el hueco del vientre se hallaba en vez del vientre; podrías creer que el pecho le colgaba y que no se sostenía más que por el enrejado de la espina dorsal. Su delgadez había hecho sobresalir sus articulaciones y la rueda de las rodillas estaba hinchada y los talones presentaban una enorme protuberancia.

\section{Ovidio. Las Metamorfosis}

\section{Introducción}

Como superficie de inscripción de signos y símbolos, el rostro ha sido un fragmento privilegiado del cuerpo a lo largo de la historia, a partir del cual se han elaborado mapas de los sentimientos, las pasiones y las facultades del alma. Feijóo es testigo directo del resurgir de la patognomonía durante el siglo XVIII. De esta manera, el benedictino dedica dos de sus discursos a la fisiognomía: "Fisionomía" y "Nuevo arte fisionómico". En el primero, despliega varios argumentos para falsear los presupuestos de la fisiognomía. En el segundo, trata de demostrar que existe una fisiognomía falsa y otra verdadera. El examen del rostro como superficie de inscripción de signos que se rigen por determinadas reglas, le sirven al padre, entre otras cosas, para afirmar el dominio y control del alma sobre el cuerpo.

\section{La fisiognomía}

Comencemos con la definición que el padre tiene acerca de la fisiognomía: "Esta voz Fisionomía significa un arte que enseña a conocer por los lineamentos externos y color del cuerpo, las disposiciones internas que sirven a las operaciones del alma". (Feijóo, 1733, T. C., t. 5, disc. 2:32-62) ${ }^{3}$. Subraya además que hay una diferencia entre la fisiognomía, que se basa en la figura corporal, y la metoscopía

${ }^{3}$ En adelante citaremos el Teatro Critico utilizando las siguientes iniciales: $\mathbf{T}$. C. En la obra en formato digital no se enumeran las páginas de los discursos, pero aparece una referencia indicando la primera y la última, así como el año de publicación de cada tomo. Esta es la referencia numérica que utilizamos aquí. que se ocupa exclusivamente de la cara. No obstante, el padre no hace ninguna referencia a esta última como el saber que desde la Edad Media unía alquimia, magia, astrología y a la fisiognomía como tal.

En efecto, enmarcada en el saber de la semejanza y en su concepto central del hombre como microcosmos, la metoscopía analiza diferentes partes del cuerpo humano de acuerdo con los elementos y el zodíaco.

Gracias a las figuras de la semejanza (la Conveniencia, la Emulación, la Analogía, la Simpatía y Antipatía) se establecen correspondencias entre el macrocosmos y el microcosmos. Así, la Analogía, como superposición de la Conveniencia y la Emulación, establece correspondencias e influencias de los planos intelectual o divino, celeste 0 astral y terrestre o elemental del macrocosmos con el microcosmos. Pero es sobre todo en el rostro donde el cuerpo humano presenta sus correspondencias planetarias y zodiacales. Según la descripción de Patricia Magli:

La frente se corresponde con Marte, el ojo derecho con el sol, el ojo izquierdo con Venus, la oreja derecha con Júpiter, la izquierda con Saturno, la nariz con la Luna, la boca con Mercurio. En cuanto a los signos del zodíaco, Cáncer preside la frente, Leo la ceja derecha, Virgo la mejilla derecha, Escorpio la nariz y así sucesivamente. Se trata de una administración del cuerpo burocratizada de modo obsesivo hasta el último dedo del pie. Existe una 
fisiognómica de las marcas como existe una medicina de las marcas: la relación entre las virtudes ocultas de las cosas y las entidades celestes que las proporcionan se expresa mediante aquellos aspectos formales de las cosas que se corresponden con los aspectos formales de los astros. Como signo de su dominación, los astros marcan al hombre desde su nacimiento. Este signatum se expresa también a menudo a través de la forma exterior del cuerpo. Saturno confiere memoria y paciencia; Júpiter, juicio y prudencia; Marte, valentía e ira; el Sol, sabiduría, moderación y magnificencia; Mercurio, imaginación y memoria. (Magli, 1999:111)

Ahora bien, Feijóo considera la fisiognomía, al igual que todas las artes adivinatorias, como simples nombres a los que les falta el objeto que designan:

¿Qué significa esta voz Astrología? Un arte de pronosticar o conocer los sucesos futuros por la inspección de los Astros. Gran cosa sería tal arte, si lo hubiese; pero la lástima es que sólo existe en la fantasía de los hombres ilusos. ¿Qué significa esta voz Chrisopeya? Un arte de trasmutar los demás metales en oro. iGran cosa sin duda! ¿Pero dónde está esa señora? Distante de nosotros muchos millones de leguas, pues no salió hasta ahora de los espacios imaginarios. (Feijóo, 1733, T. C., t. 5, disc. 2:32-62).

Para el benedictino, el supuesto fundamento de la fisiognomía es sólo una "conjetura" según la cual existe una "proporción" entre el alma (la forma) y el cuerpo (la materia). Así, las diferentes especies de animales tienen una conformación específica en sus órganos internos y externos que se corresponden con distintas almas. La figura, es decir, el aspecto físico de tal o cual especie, es la imagen del alma. De la especie se pasa a los individuos (como en el caso de los humanos), quienes presentan características particulares permanentes tanto físicas (forma del cuerpo, "textura y color") como morales (vicios, virtudes, pasiones, afectos, etc.). Presentes en cada individuo, estas características no son sino la parte "accidental que hay dentro de cada especie [...] salvando la uniformidad esencial de la especie". (Feijóo, T. C., t. 5, disc. 2:32-36. El subrayado es nuestro).
Luego pasa a describir las reglas generales que rigen la fisiognomía en general, las cuales se basan en cinco principios: el primero, se funda en la analogía cuyos términos de comparación son las figuras (las formas externas) de los animales con las de los hombres. El segundo, establece semejanzas teniendo como punto de partida otros hombres "cuyas cualidades se suponen exploradas". El tercero, relaciona tal o cual color 0 aspecto de la cara con una virtud, vicio o pasión; así, por ejemplo, la cara roja es signo y marca permanente de una persona verecunda. El cuarto, se basa en la teoría antigua y medieval de los humores y temperamentos. Y finalmente, el quinto toma como punto de comparación la representación del otro sexo: el hombre se compara con la mujer y viceversa, tomando elementos tales como el color de la piel o el tamaño del cuerpo. El padre examina entonces cada uno de estos principios para mostrar que son "vanos, antojadizos y desnudos de razón”.

El primer principio se conoce en la historia de la fisiognomía como fisiognómica zoológica.

Sus orígenes se remontan a las primeras fábulas y a las innumerables versiones de los bestiarios. Así, Aristóteles consideraba que la estructura corporal de los animales era más simple y por lo tanto más fácil de describir y entender que la de los hombres y, de este modo, establece semejanzas entre éstos para aislar el carácter de los individuos; como lo explica Magli:

Los animales, fijados en imágenes emblemáticas, funcionan como un espejo invertido a través del cual es posible reconocer las pasiones, los vicios y las virtudes de los hombres. El mundo de los hombres por su parte no es sólo el punto de llegada de este proceso de semiosis, sino que también se constituye como elemento 
interpretante que da origen a otro proceso semiótico de retorno hacia el animal. (Magli, 1999: 98).

En síntesis, ésta es básicamente la estructura y la función que la fisiognómica zoológica conservará hasta el siglo XIX: clasificación de caracteres morales que resultan de la comparación de partes del cuerpo humano (nariz, frente, boca, arrugas, color de la piel, piernas, etc.) con sus análogas en los animales.

En su texto Feijóo se refiere a Giambattista Della Porta, fisiognomista del Renacimiento quien escribió un tratado titulado De Humana Physiognomia. En este último aparecen dibujos de cabezas o cuerpos de animales (cargados tradicionalmente de vicios, virtudes y pasiones) al lado de cabezas de personas que en algunos de sus rasgos se asemejan al animal:

Esta comparación, nos dice Magli, se funda sobre la analogía que, en el interior del entimema fisiognómico, se convierte en el fundamento mismo del mecanismo de correlación. Tomemos el caso del Hombre-Pájaro. Los pájaros son móviles, vanos y locuaces, [...]. Los pájaros están dotados de una cabeza pequeña. Y por ello aquellos hombres que están dotados de una cabeza pequeña, serán, como los pájaros, móviles, vanos y locuaces”. (Magli, 1999:103).

De esta manera, frente a la conclusión del silogismo de Della Porta, el benedictino pregunta: "¿quién no ve, por más que se parezca un hombre al león en la figura, mucho más se parecerá a otro hombre que es tímido? ¿Cómo, pues, puede preponderar para creerle animoso la semejanza imperfectísima que tiene con un animal robusto y atrevido, sobre otro mucho más perfecta, con un animal cobarde?". (Feijóo, T. C., t. 5, disc. 2:32-62).

El padre pone en duda las correspondencias y su mecanismo, pues considera que los signos físicos no encajan punto por punto con las cualidades 0 facultades morales:
[Della Porta] hizo estampar en su obra las figuras de varios hombres, careadas con otras de algunas especies de brutos; pero tan infelizmente, que este careo más sirve al desengaño que a la persuasión. Porque (pongo por ejemplo) aparecen allí la figura de Platón y la del emperador de Galba, sacadas de antiguos mármoles, cotejadas y con alguna, aunque diminutísima semejanza, la primera a la de un perro de caza y la segunda a la del águila. ¿Qué semejanza tuvieron en las cualidades del ánimo, ni Platón con un perro, ni Galba con el águila? Antes bien cuadraría mucho mejor la semejanza del águila a Platón, por lo generosos y elevados vuelos de su ingenio. (Feijóo, T. C., t. 5, disc. 2:32-62).

Pero el benedictino no sólo se detiene en el examen de las semejanzas en la figura, también hace referencia al comportamiento de los animales que, siguiendo también otra antigua tradición, se convierten en emblemas del arte, la ciencia y el orden social, político y moral:

Muchos brutos muy estúpidos son mucho más semejantes al hombre en la figura que el Elefante: no obstante lo cual, éste se parece mucho más que aquellos al hombre en la facultad perceptiva del alma. ¿Qué diremos del gobierno económico de las hormigas? ¿De la sagaz conducta de las abejas? Estas dos especies de animalillos distan infinito de la figura, textura, y color del hombre: sin embargo de lo cual imitan la industria y gobierno civil del hombre con suma preferencia a otros brutos, cuya traza corporal se acerca mucho más a la nuestra. (Feijóo, T. C., t. 3, disc., 9:187-223).

En este discurso titulado "Racionalidad de los brutos" sostiene la idea, según la cual del animal al hombre existe una serie jerárquica de facultades perceptivas y cognitivas.

Este texto se compone de una gran cantidad de anécdotas que describen comportamientos y actitudes semejantes a las del hombre en distintos animales. En resumen, este 
discurso defiende la idea de que los animales están dotados de un alma, que aun siendo material, posee facultades muy similares a la humana. En el fondo, se trata de "devolverle" a los animales lo que habían perdido ("sentimiento", "discurso" y "razón”) debido al mecanicismo de Descartes "quien afirmó que no son los brutos otra cosa que unas estatuas inanimadas, cuyos movimientos dependen únicamente de la figura y disposición orgánica de sus partes, según la varia determinación que les da la unión de los objetos que las circundan". (Feijóo, T. C. t. 3, disc, 9:187-223). Como vemos, a pesar de señalar los puntos débiles de las semejanzas y su mecanismo, el padre sigue atrapado en el juego de espejos que la fisiognomía había instaurado entre los hombres y los animales ${ }^{4}$.

El segundo principio también se basa en un cara a cara, pero toma como punto de partida las sobresalientes cualidades físicas y morales de individuos sobrecargados con signos que, de antemano, los convierten en figuras modelo. Feijóo se refiere al tratado de fisiognomía del jesuita Honorato Niquet (del cual incluye un extenso cuadro de correspondencias que inserta al final de su discurso) para tomar de allí el ejemplo de los rasgos físicos ("catorce señales") que convergen para caracterizar a un hombre de "buen ingenio": "Carne blanda, cutis delgado, mediana estatura, ojos azules o rojos, color blanco, cabellos medianamente duros, manos largas, dedos largos, aspecto dulce 0 amoroso, cejas juntas, poca risa, frente abierta, sienes algo cóncavas, la cabeza que tenga figura de mazo". (Feijóo, T. C., t. 5, disc. 2:32-62).

El padre falsea este tipo de correspondencias subrayando que estas mismas señales se pueden encontrar en hombres que no son inteligentes, lo que las convierte en signos ambiguos, que igualmente sirven para caracterizar a los estúpidos. Por lo demás, a medida que aumenta el

${ }^{4}$ Acerca del comportamiento de los animales como modelo social y cultural, véase Jean Pierre Albert, La Ruche d Aristote: science, philosophie, mythologie, en L Homme, Vol. 29, N. 110, París, 1989. número de señales físicas, es "imposible la observación" de las correspondencias en el plano moral y el valor demostrativo de este principio fisiognómico termina por desvanecerse: "Yo he visto y tratado muchos hombres ingeniosos, concluye el benedictino, pero en ninguno he encontrado este complejo de señas. ¿Cómo podrá, pues, la observación experimental asegurarnos de que hay alguna verdad en esta materia?". (Feijóo, T. C., t. 5, disc. 2:32-62). El tercer principio afirma que existen signos físicos permanentes en la cara que se corresponden con pasiones fijas. Así, por ejemplo, la cara pálida es signo de debilidad y pusilanimidad y la roja de verecundia. En el caso de la segunda, la vergüenza es la pasión dominante que produce este color de manera permanente. Pero Feijóo precisa que hay una diferencia entre la actualización de esta pasión que hace fluir la sangre hacia la cara, percibiéndose así como señal (el sonrojarse) y el aspecto "habitual y estable" de la cara roja que tendría su origen en la estructura y función de las "venas capilares": "que discurren por el ámbito del semblante, son anchas, y por consiguiente reciben mayor copia de sangre. Acaso también, porque por ser más delgadas y transparentes sus túnicas, juntamente con el cutis, se hace más visible aquel rojo licor y se representa el rostro bañado de color sanguíneo". (Feijóo, T. C., t. 5, disc. 2:32-62). Así, al señalar estas dos posibles causas del color rojo de la cara, muestra una vez más el carácter "antojadizo", hoy diríamos arbitrario, de las correspondencias entre las pasiones, las formas y los colores de la cara.

El cuarto principio se basa en las correspondencias que desde la Antigüedad se establecieron entre los elementos, los humores y los temperamentos, a los que se agregaron cuatro animales emblemáticos; así, por ejemplo: "el colérico tiene la naturaleza del fuego y también la del león; el flemático, la del agua y la del cordero; el sanguíneo, la naturaleza del aire y del mono; el melancólico, la de la tierra y el cerdo". (Magli, 1999:106). 
Ahora bien, el benedictino señala que este principio está compuesto por una parte verdadera y una falsa. La parte verdadera se fundamenta en que las pasiones dependen de los temperamentos: "He dicho en gran parte, por no quitar la que se debe conceder a la organización [anatómica]". (Feijóo, T. C., t. 5, disc. 2:32-62). Por lo tanto, en este punto el padre sigue y acepta como verdad la teoría hipocrática de los temperamentos (colérico, melancólico, sanguíneo y flemático) según la cual éstos resultan de la combinación de cualidades (cálido, húmedo, seco, frío), elementos (aire, fuego, agua, tierra), humores (cólera, bilis, sangre, flema), así como de las estaciones, vientos y edades. No obstante, el padre subraya que "en lo respectivo precisamente a la medicina es impenetrable el temperamento"; pues si bien se pueden diagnosticar y curar, según la medicina hipocrática, algunas enfermedades de acuerdo con la naturaleza de tal o cual temperamento, considera como falso el supuesto de que se pueda inferir el carácter permanente o la pasión dominante de un individuo, a partir de un elemento que se origina y muta de acuerdo con las combinaciones de los otros elementos:

Lo que no tiene duda es que no hay medio alguno para conocer el temperamento individual de cada hombre con aquella determinación que se requiere para juzgar de su índole, capacidad, afectos [...]. ¿Qué haremos con saber (si aun siquiera eso se puede conocer por el rostro), que este es pituitoso, aquel melancólico, el otro colérico, sanguíneo? ¿Quién no observa cada día dentro de cualquiera de las nueve clases de temperamento que establecen los Galénicos, hombres de diversísima índole y capacidad? Hay sanguíneos (pongo por ejemplo) de excelente ingenio y sanguíneos muy estúpidos; sanguíneos de bella índole y sanguíneos de perversas inclinaciones; sanguíneos mansos y sanguíneos fieros; sanguíneos animosos como leones y sanguíneos tímidos como ciervos. (Feijóo, T. C., t. 5, disc. 2:32-62).

En el quinto principio es la mujer la que se convierte en imagen y símbolo, es decir, en espejo de partida: en su cara también se puede leer un código de valores morales.
Así, por ejemplo, el color blanco y la piel blanda en algunos hombres es signo de debilidad y cobardía, puesto que son signos permanentes de la feminidad. Con respecto a este punto de partida, que hace proliferar las correspondencias en este principio, el padre dice que su falsedad se descubre con la experiencia cotidiana, "pues a cada paso se ven hombres muy blancos y muy animosos y valientes. Los habitadores de las regiones septentrionales, que son mucho más blancos que nosotros, son también más fuertes y más audaces”. (Feijóo, T. C., t. 5, disc. 2:32-62).

Así pues, con estas "pruebas" y "experiencias", el benedictino muestra la "vanidad de las reglas generales de la fisionomía" y agrega que "ocioso es impugnar las particulares [las fisiognomías]; pues éstas se infieren de aquellas y nunca puede de antecedente falso salir consiguiente verdadero". (Feijóo, T. C., t. 5, disc. 2:32-62).

Por otro lado, Feijóo acepta que existe un "comercio" entre el cuerpo y el alma, pero critica las correspondencias simpáticas que, desde el saber de la semejanza, establece Della Porta entre éstos. Para este último, el cuerpo y el alma se relacionan de la misma manera que la materia y la forma, pues como lo señala Magli:

No existe escisión u oposición entre Dios y el mundo, cuerpo y alma, sino que una sola fuerza actúa a través de una continuidad de relaciones. En este contexto, el orden natural y el humano no se hallan contrapuestos sino que se encuentran unidos: el destino del hombre se prolonga en los acontecimientos naturales y éstos se enriquecen con profundas vibraciones espirituales. (Magli, 1999:107).

El benedictino enfrenta pues estas correspondencias simpáticas entre el alma y el cuerpo subrayando la diferencia entre el cuerpo mortal (escenario de placeres y sufrimientos) y el alma inmortal (lugar de la "representación objetiva" de las afecciones del cuerpo); en consecuencia: 
Es el cuerpo, no sólo instrumento, más también sujeto en quien obra el alma. Ésta, ni es sujeto ni instrumento del cuerpo. Así, aunque herido el cuerpo o postrado con una enfermedad, se duele el alma, se contrista y padece alguna decadencia en sus facultades, esta comunicación no se bace por medio de algún influjo activo del cuerpo al alma; si sólo de la representación objetiva del mal del cuerpo, el cual el alma no puede menos de sentir, como propio, en fuerza de la unión natural que tiene con él. (Feijóo, T.C., t. 5, disc., 3:63-72. El subrayado es nuestro).

De este modo, las simpatías y antipatías que, a través de sus infinitas correspondencias, le permiten al fisiognomista hacer de la cara el espejo del alma y descifrar sus signos permanentes, se convierten para Feijóo en "Contrabando de la Filosofía y fraude de la Escuela".

\section{Las dos fisiognomías}

El padre introduce entonces la descripción de un "Nuevo Arte fisionómico" para oponerlo a la fisiognomía vulgar y falsa que acaba de examinar. En efecto, el padre se refiere aquí, en términos generales y sin nombrarla de este modo, a la patognomonía

La comunicación del alma al cuerpo se ejerce con verdadera y rigurosa causalidad. Apenas hay en el alma algún afecto a quien no corresponda en el cuerpo algún efecto. Los pasos del espíritu imprimen la buella en el semblante. En éste está la sombra, cuyo movimiento señala el curso del Astro que le rige. La vergüenza, llevando la sangre al rostro, le baña de una honesta confusión; la ira, precipitándola tumultuariamente, le viste de una turbación

\footnotetext{
${ }^{5}$ Este término era utilizado en medicina como sinónimo de "semiología o estudio de los signos (de las enfermedades); la patognomonía sería el conocimiento de los signos patológicos (indicios de las enfermedades)". Lavater la emplea en el sentido de "conocimiento de las pasiones", que debe entenderse como el conjunto de los "movimientos del alma", y lo que nosotros llamaríamos más bien emociones, "movimientos (del alma)". (Guiraud, 1994:30).
}

feroz; el miedo, retirándola, le desnuda del nativo color; el placer le aviva moderadamente, serena los ojos y dilata un poco toda la textura de la cara; el afecto de risa, la varía considerablemente. (Feijóo, T.C., t. 5, disc., 3:63-72. El subrayado es nuestro).

Si la fisiognomía trata de "congelar" los rasgos de los individuos para clasificarlos y codificarlos e inferir de allí pasiones, vicios y virtudes permanentes, la patognomonía parte de las pasiones que se originan en el alma y que emergen en el rostro como signos naturales, los cuales también se pueden codificar e interpretar de acuerdo con valores sociales, culturales y morales. La patognomonía también deduce el carácter de los individuos, pero observando el movimiento de las partes de la cara y sus sutiles relaciones (frente, cejas, mejillas, labios, ojos, nariz), de antemano convertidas en signos, en el momento en que las pasiones se expresan a través de ellas.

Entonces, aparentemente, la patognomonía se diferencia de la fisiognomía, pero la primera está subordinada a la segunda, pues ambas tienen como finalidad el estudio del carácter.

Según la patognomonía cada individuo nace con una fisonomía esculpida directamente por Dios. Pero esta fisonomía toma sentido cuando se pone en movimiento en el transcurso de la vida de los individuos, que se expresan a través de este lenguaje natural doblado a su vez por un lenguaje artificial, y cuyos códigos y reglas se pueden aprehender.

Como en el caso de la fisiognomía, la patognomonía trataba entonces de clasificar y codificar este "saber inmemorial" describiendo, pero igualmente "congelando" los movimientos de la cara a partir de los cuales se expresan las pasiones; y no podría ser de otra manera, pues en tanto dominada por las taxonomías de los caracteres de la 
fisiognomía (basadas en imágenes y esculturas de rostros), la patognomonía dejaba por fuera, en este punto de su historia, el componente fisiológico, es decir, el estudio sistemático de los movimientos de las partes de la cara como signos de las pasiones. Como lo subraya François Delaporte:

Puede ocurrir que la patognomonía confirme el valor de un signo. Para estar seguros de que dos caracteres se parecen, es preciso observar el momento en que se ponen en movimiento. Si la línea que nace del movimiento de los músculos es la misma en los dos rostros, entonces la conformidad del espíritu no puede ponerse en duda. Pero, con frecuencia, las mímicas dificultan el estudio del carácter. En la medida en que las disposiciones originales están inscritas en las partes sólidas, la fisonomía en movimiento las oculta. Cada uno de nosotros tendría una fisonomía primitiva cuyo origen y esencia serían divinas. Se restablecería en la calma de la muerte, como el agua enturbiada se aclara cuando deja de ser agitada. (Delaporte, 2007:56-57).

En este marco Feijóo pretende establecer una diferencia entre una fisiognomía falsa y otra verdadera. Para demostrar una vez más la falsedad de la primera recurre al ejemplo del cadáver, en cuyo rostro dejan de percibirse los signos que le daban un carácter. Para el benedictino lo único que se puede apreciar en el cadáver son los signos naturales ("los lineamientos del cuerpo o del rostro") que en vida y en movimiento expresaban "las disposiciones del ánimo". Así pues, el lenguaje codificado y reglamentado que la fisiognomía "falsa" desliza sobre el lenguaje natural, desaparece, en tanto artificial y arbitrario, con la inercia de la muerte:

Nótese ahora, que por más que contemplemos un cadáver, nunca nos envía especie alguna, de si fue ingenioso o rudo, iracundo o manso, animoso o tímido, triste o melancólico el sujeto cuando vivo. Como es cadáver en sí mismo, lo es también para nosotros: quiero decir, no produce en nuestra fantasía idea alguna de las cualidades del espíritu, que antes le informó. Cuerpo es y no más: cuerpo y no más concebimos. Así, por más que le examinemos, quedamos en una perfecta indiferencia para asentir a los informes que nos hicieren los que le conocieron. (Feijóo, T.C., t. 5, disc., 3:63-72).

Por consiguiente, la fisiognomía verdadera, es decir, la patognomonía y su estudio de la fisonomía en movimiento que expresa las pasiones del alma, se revela en positivo en contraste con la falsa:

\begin{abstract}
Esta representación natural no puede consistir en otra cosa que en varios, sutiles y delicados movimientos que de las varias disposiciones del alma resultan al cuerpo, especialmente al rostro y sobre todo a los ojos. La razón es clara; porque todo lo que percibe la vista en el cuerpo vivo, persevera en el cadáver, exceptuando el movimiento. La figura es perfectamente la misma; aún el color estable es el mismo; de modo, que en él se distinguen el rubio, el blanco, el moreno, el fusco, sin otra diferencia que aquella que da a la tez la agitación o movimiento de la sangre. (Feijóo, T.C., t. 5, disc., 3:63-72. El subrayado es nuestro).
\end{abstract}

La diferencia fundamental entre las dos fisiognomías reside, según el examen del padre, en que la falsa estudia el carácter en estado de reposo, lo que implica la inevitable consecuencia de que el alma y sus facultades están determinadas por el cuerpo, lo cual es un resultado inaceptable desde el punto de vista teológico. Por consiguiente, en la verdadera, que estudia el carácter en movimiento, la determinación se invierte y el dominio se ejerce del alma al cuerpo.

Y por si quedaran dudas respecto de la fisiognomía verdadera, vienen las pruebas tomadas de las auctoritates profanas y cristianas. En primer lugar cita a Cicerón como confirmación:

A cada movimiento del ánimo (dice) corresponde su particular semblante, sonido y gesto. Es el rostro imagen del ánimo, indices los ojos; porque esta es una parte del cuerpo, quepuede tener tantas significaciones y mutaciones, cuantos son los movimientos del ánimo. 
[...] (lib. 3. De Oratote.) El pasaje es tan claro a mi propósito, que estarían por demás toda explicación 0 comento. (Feijóo, T.C., t. 5, disc., 3:63-72.).

Pero la conclusión final la extrae nada menos que del "Divino Oráculo de la Escritura": "Cor hominis immutat vultum illius, sive in bona, sive in mala (Ecclesiastic. cap. 13): El corazón del hombre inmuta su semblante. Esto es, a cada afecto o pasión del ánimo corresponde algún especial movimiento en el rostro; y a cada movimiento especial, especial gesto o configuración”. (Feijóo, Benito, T.C., t. 5, disc., 3:63-72.).

A pesar de las conclusiones negativas con respecto a la falsa fisiognomía, y sin insistir mucho en esto,

el padre ve un lado positivo y verdadero en esta facultad, "pues le es importantísimo al hombre para todos los usos de la vida civil conocer el interior de los demás hombres". (Feijóo, Benito, T.C., t. 5, disc., 3:63-72). Como lo muestra Jean-Jacques Courtine, la fisiognomía no sólo tenía como finalidad constituirse como un saber a través de su historia, su praxis también estaba íntimamente ligada con las normas, los códigos y las reglas que rigen la vida social y cultural, es decir, con la urbanidad:

La fisiognomía es portadora de una historia de la mirada sobre el cuerpo. Hace más que descifrar los lenguajes del alma "extendida por fuera". Fomenta normas corporales, establece una definición "media" de la fisiognomía, descubre en la proporción el tipo ideal de la belleza, rechaza hacia las márgenes de la mirada distorsiones, deformaciones, monstruosidades. [...]. Prescribe técnicas del cuerpo, legitima habitus, reprueba y sanciona ciertas prácticas. Responde de hecho a un deseo de transparencia individual y social y quiere asegurarse identidades e intenciones cuando su percepción se vuelve confusa [...].
Participa además de la construcción de las discriminaciones sociales y de las diferenciaciones sexuales en el campo de la mirada. (Courtine, 2005:295-296).

\section{Conclusión}

Como resultado de su examen, el padre establece una distinción entre una fisiognomía falsa y otra verdadera. La falsa crea relaciones y correspondencias entre el alma (sede de caracteres, pasiones, inclinaciones, sentimientos y emociones) y el cuerpo (portador de huellas, marcas, indicios, rasgos físicos, etc.). Su falsedad está determinada por la concepción tradicional de la dualidad cuerpo-alma y el lugar jerárquico que ocupan; para el benedictino, en un contexto cristiano, es indiscutible que el alma y sus facultades gobiernan el cuerpo.

En síntesis, para Feijóo el error que excluye a este saber de la verdad consiste en la dirección de la lectura de los signos, los cuales parten del rostro, o de otras partes del cuerpo, para determinar y descifrar las facultades y potencias del alma que, por lo demás, forman el carácter dominante en un individuo y permanecen estables durante toda su vida. El padre considera entonces que la verdadera fisiognomía (léase patognomonía) es aquella que invierte la dirección de la lectura de los signos: el alma se expresa a través de los signos en movimiento inscritos en un cuerpo que domina y está a su servicio hasta la muerte. El análisis de este caso nos muestra el proceso de reinterpretación y, en consecuencia, la utilización de las nociones generales de un saber para afirmar presupuestos teológico-morales; pero también nos permite ver cómo afloran algunas representaciones de un cuerpo cristiano dividido en un espacio interior (lo oculto e invisible) y exterior (superficial y manifiesto). Y en este punto podemos escuchar una vez más el conocido eco del martillo:

El juicio moral no puede nunca ser tomado el pie de la letra: como tal no contiene más que un contrasentido. 
Pero conserva un valor inapreciable como semiótica, porque revela al menos docto las más preciosas realidades de la civilización, y aquellas interioridades que no sabían bastante para comprenderse a sí mismas. La moral es simplemente un lenguaje de signos, simple sintomatología: se debe saber de qué se trata para obtener utilidad de él. (Nietszche, 1972:79-80).

\section{Bibliografía}

Albert, Jean-Pierre (1989). "La Ruche d'Aristote: science, philosophie, mythologie". En l'Homme, Vol. 29, $\mathrm{N}^{\circ} 110$.

Courtine, J. J. (2005). "El espejo del alma". En Corbin, Alain et al., Historia del cuerpo, Madrid, Taurus, Vol I.

Courtine, J. J. (2005). "El cuerpo inhumano". En Corbin, Alain et al., Historia del cuerpo, Madrid, Taurus, Vol. I.

Feijóo, B. (1726-1740). Teatro Crítico Universal. Discursos Varios en todo género de materias, para desengaño de errores comunes. [En línea] http://www.filosofia.as/ feijoo

Feijóo, B. (1742-1760). Cartas eruditas y curiosas en que, por la mayor parte, se continúa el designio del Teatro Crítico Universal, impugnando, o reduciendo a dudosas, varias opiniones comunes. [En línea] http:// www.filosofia.as/feijoo

Changeux, P. (1986). "El órgano del alma, desde el antiguo Egipto a la Belle Époque". En El Hombre neuronal, Madrid, Espasa-Calpe.

Darwin, Ch. (1998). La expresión de las emociones en los animales y en el hombre, Madrid, Alianza.

Delaporte, François. 2007. Anatomía de las pasiones, Barranquilla, Universidad del Norte y Universidad de Picardie Jules Verne.
Delaporte, François. (2002). Filosofía de los acontecimientos, Medellín, Universidad de Antioquia y Universidad de Picardie Jules Verne.

Delpy, G. (1936). Bibliographie des sources françaises de Feijóo, París, Hachette.

Foucault, M. (1982). Las palabras y las cosas. Una arqueología de las ciencias humanas, México, siglo XXI.

Guiraud, P. (1994). El lenguaje del cuerpo, México, F. C. E.

Le Breton, A. (1999). Las pasiones ordinarias. Antropología de las emociones, Buenos Aires, Nueva Visión.

Le goff, J. (1999). “iLa cabeza o el corazón? El uso político de las metáforas corporales durante la Edad Media". En Feher, Michel. (Comp.), Fragmentos para una bistoria del cuerpo bumano, Madrid, Taurus.

Magli, P. (1999). "El rostro y el alma". En Feher, Michel, (Comp.), Fragmentos para una bistoria del cuerpo bumano, Madrid, Taurus.

Nietzsche, F. (1972). El ocaso de los ídolos, Barcelona, Tusquets.

Schmitt, J. C. (1999). "La moral de los gestos". En Feher, Michel, (Comp.), Fragmentos para una historia del cuerpo bumano, Madrid, Taurus.

Soto Posada, G. (2001). La función de la semejanza en las Etimologías de San Isidoro de Sevilla, Medellín, Universidad Pontificia Bolivariana.

Zapata Cano, R. (2007). "La dimensión social y cultural del cuerpo". En Boletín de Antropología $\mathrm{N}^{0} 37$, Medellín, Universidad de Antioquia. 


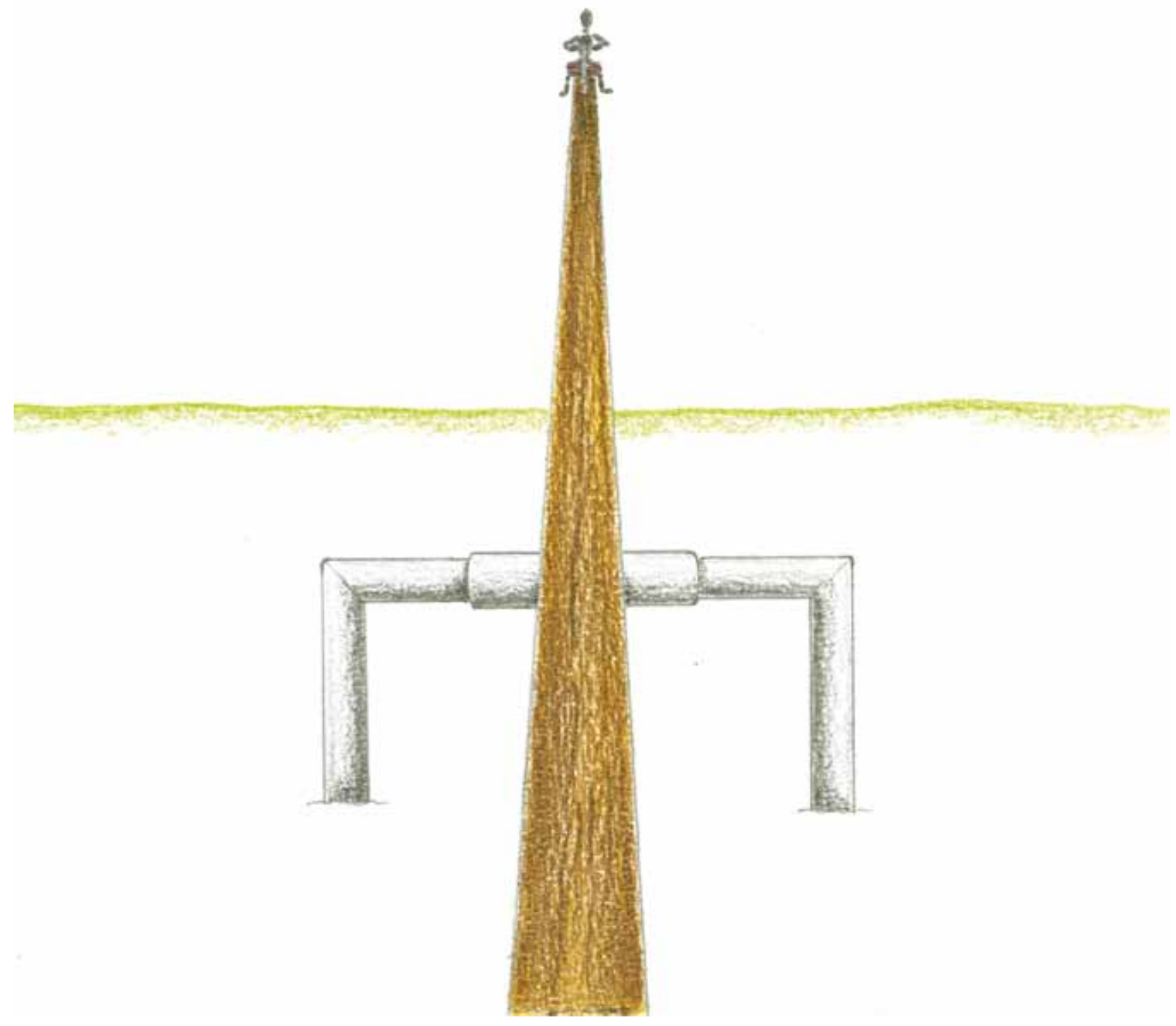




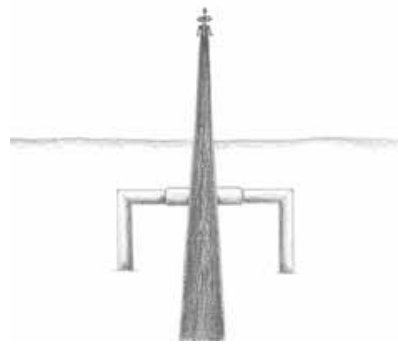

MATACULÍ́

Técnica mixta

Frank Vélez Penagos 